\title{
«ESTE ES EL TIEMPO DE BAILAR»: LA DANZA COMO DIÁLOGO CELEBRATIVO EN LOS CUENTOS JASÍDICOS, DE MARTIN BUBER
}

\author{
Felipe Agudelo Olarte ${ }^{1}$ \\ Universidad de Tubinga (Alemania) \\ agudelofelipe2002@hotmail.com
}

Recibido: 15/02/2020 - Aprobado: 01/04/2020

DOI: doi.org/10.17533/udea.lyl.n78a18

\begin{abstract}
Resumen: Los Cuentos jasídicos, de Martin Buber, son abordados en el presente artículo desde la presencia de la danza como motivo temático en algunos de los relatos, buscando así acercarse al pensamiento del autor a través de su obra literaria. En el texto se relacionan los relatos con elementos de estructura narrativa; se presenta el diálogo como marco narrativo de los cuentos en los contextos de lo incomprensible, la identidad, la comunidad-amistad y la muerte; finalmente, se propone la danza como «esfera del entre» en los cuentos y condición de celebración del encuentro yo-tú, efectuado en quienes participan de la trama.
\end{abstract}

Palabras clave: Martin Buber; Cuentos jasídicos; danza; diálogo; celebración.

\section{«THIS IS THE TIME TO DANCE»: DANCE AS A CELEBRATORY DIALOGUE IN MARTIN BUBER'S TALES OF THE HASIDIM}

\begin{abstract}
Martin Buber's Tales of the Hasidim are addressed in this article from the presence of dance as a thematic motif in some of the stories, seeking thus to approach the thought of the author through his literary work. In the text, stories are related with elements of narrative structure; dialogue is presented as a narrative framework of stories in the contexts of the incomprehensible, identity, community-friendship and death; finally, dance is proposed as «sphere of the between» in the stories and a condition of celebration of the I-you meeting, held in those who participate in the plot.
\end{abstract}

Key words: Martin Buber; Tales of the Hasidim; dance; dialogue; celebration.

1. El artículo se gestó para optar al título de Magíster en Hermenéutica Literaria de la Universidad Eafit (Colombia).

LINGÜÍSTICA Y LITERATURA 


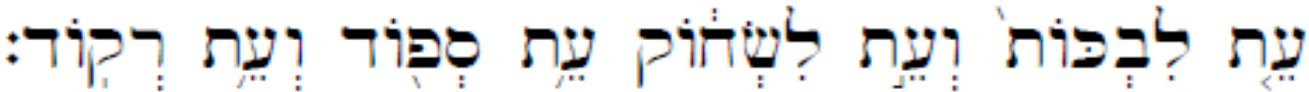

«Hay tiempo de llorar y tiempo de reír; tiempo de lamentarse y tiempo de bailar»

Eclesiastés 3, 4 .

\section{Introducción: Sordos ante al baile}

Rabí Moshé Jaím Efraím, nieto del Baal Shem, contó: «Yo oí decir a mi abuelo que una vez un violinista tocó tan dulcemente que todos los que lo oían comenzaron a bailar, y los que se acercaron a escucharlo también se unían a la danza. Entonces un sordo, que nada sabía de música, acertó a pasar por allí y le pareció que todos actuaban como locos, desprovistos de gracia y de sentido» (El sordo, 1993, p. 110).

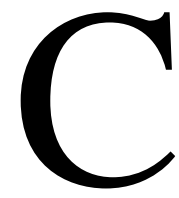

omo en este relato de sus Cuentos jasídicos, Buber retoma en varios de ellos el elemento de la danza como acción que en el marco de un diálogo es vivida por uno o varios de los personajes. El pensamiento dialógico de este filósofo alemán consiste en una invitación a la vida auténtica, la cual es según él, la que se da en el encuentro yo-tú marcado por la reciprocidad (Buber, 1969, p. 16). Asimismo, lo hizo en estos textos literarios, en los que con la imagen de la danza invita a otros a unirse a la música del encuentro que ha hecho parte de la corriente jasídica y que ha influenciado su pensamiento.

A través de los relatos, el autor sugiere a los lectores escuchar en cada narración el diálogo que se da entre los personajes, descubriendo un sentido de la vida en lo que acontece a través de acciones y palabras. Cada voz que comienza el cuento es como el violinista del relato que atrae; sin embargo, también Buber hace una advertencia sobre la actitud de cerrarse ante la música del encuentro que une a quienes danzan, como le sucede al sordo sin conocimiento de la música.

El camino del presente trabajo, en el que se hará un acercamiento a los Cuentos jasídicos desde el motivo temático de la danza, estará dado en un primer momento por una introducción a los cuentos y su relación con la danza, la presentación de los textos seleccionados por la presencia de la danza en ellos y una relación entre algunos elementos 
de estructura narrativa y el motivo temático que sirve de perspectiva para la propuesta de lectura. Luego, se abordará el diálogo como marco en el cual se desenvuelven los relatos y cuatro contextos en los que se da una recurrencia de la danza en las historias, los cuales son: lo incomprensible, la identidad, la comunidad-amistad y la muerte. En el último segmento, se analizará el concepto de la «esfera del entre», (en alemán, Zwischen) de la filosofía de Buber y se presentará la propuesta de releer la danza en los cuentos como esta esfera de encuentro y celebración del diálogo que se desarrolla en los relatos.

\section{2. «Se cuenta que...» La danza como motivo temático en algunos Cuentos jasídicos, de} Martin Buber

En este primer segmento se hará una aproximación textual a los Cuentos jasídicos, del filósofo judío Martin Buber; luego, se presentarán los cuentos seleccionados en los que aparece la danza como motivo temático y algunos elementos de la estructura narrativa que posibilitarán una mayor comprensión de los relatos y del papel de la danza en ellos.

\subsection{Apuntes sobre los Cuentos jasídicos de Buber y la presencia de la danza en ellos}

Los Cuentos jasídicos se inscriben en el ámbito del jasidismo, un movimiento judío que tiene su origen durante el siglo XVII en Podolia y Wohlynia, cuyo fundador fue Israel ben Eliezer (1700-1760), llamado el Baal Shem posteriormente. J. H. Laenen (2006) especificó que desde sus inicios el jasidismo «no prestaba demasiada atención al estudio intelectualmente agotador de la Torá y del Talmud que practicaban los rabinos de su tiempo» (p. 242), permitiendo una mayor acogida en la gente sencilla del pueblo. Esta corriente se encuentra marcada por la conciencia de la importancia de la actividad cotidiana, en la cual se busca aún en el acto simple un significado profundo, así como por la alegría como distintivo de quienes llevan una vida de piedad.

La vida de las comunidades jasídicas estaba centrada en el tzadik ${ }^{2}$ como centro espiritual (Laenen, 2006), de ahí la importancia del recuerdo permanente de los maestros

1. Nombre que recibe el líder espiritual de la comunidad jasídica y cuya traducción hebrea es «justo». 
que habían dado origen a cada una de las comunidades, cuyas vidas recogen los cuentos como centro de su narración y que llevará en un momento tardío del jasidismo a dar a los relatos una subrayada importancia, no solo a los cuentos, sino al acto mismo de narrarlos (Laeenen, 2006).

Los cuentos jasídicos del presente estudio son los que recoge y reelabora Martin Buber ${ }^{3}$, filósofo judío de origen alemán, perteneciente al jasidismo desde su formación con su abuelo Salomon Buber (Buber, 1993), en los que se da un híbrido de actos y palabras que se asocian para formar una unidad inseparable. La danza en los relatos se hace presente y actúa como «acción simbólica», acompañada siempre por palabras que, como refirió el autor, complementan y posibilitan su interpretación. En su condición de acción «mediatizada simbólicamente», usando la expresión de Paul Ricoeur (2006, p. 18), la danza da qué pensar en los relatos frente al sentido de la vida al que ella se refiere con las características que en cada cuento le son propias.

El término de cuentos para estas historias lo determina Buber especificando que con él quiere significar «el relato de un destino que es representado por un episodio singular; la anécdota es el relato de un episodio singular que ilumina ese destino en su totalidad», enfatizando que esta anécdota es de tipo «legendaria», lo cual implica que «el episodio singular en cuestión entraña el sentido de la vida»(Buber, 1993, p. 21). Si el episodio singular de algunos relatos es la danza, ella adquiere en el texto una carga de sentido de vida que se desea transmitir y por eso su presencia en los cuentos exige un análisis para presentar el sentido que en la narración se ofrece.

Es importante señalar que, al describir el proceso de formación y selección de los cuentos, Martin Buber (1993) mencionó que su criterio para la inclusión de los cuentos en la obra fue «la propia significación de cada relato, así como su especial importancia para la

2. Mordechai Martin Buber, posiblemente el filósofo judío más significativo del siglo XX, nació en Viena el 8 de febrero de 1878. Entre Viena, Leipzig, Zúrich y Berlín estudió filosofía, historia del arte y de la literatura, psiquiatría, germanística, filosofía clásica y economía política. Buber tiene como maestros a Dilthey y a Simmel. Fue doctorado en filosofía en 1904, luego expulsado de su cátedra universitaria en Frankfurt en 1933 por los nazis, lo que lo llevó en 1938 a exiliarse en Palestina donde fue nombrado profesor en la Universidad Hebrea. Falleció en Jerusalén el 13 de junio de 1965 a los 87 años. Entre sus obras se destacan: Yo y Tú (1923), Diálogo (1932), ¿Qué es el hombre? (1942), Imágenes del bien y del mal (1952) y Eclipse de Dios (1952). A nivel literario Buber a publicado los textos: Cuentos de Rabí Naham (1906), La leyenda del Baal Shem (1907), El Gran Maguid y su sucesión (1921) y La luz oculta (1924). Estos últimos son recogidos en la obra de los Cuentos jasídicos, sobre los cuales se centra el presente artículo. 
comprensión de la vida jasídica» (p. 22). Con esto, la presencia de la danza en los relatos habla de su significación, así como de su valor en la vida jasídica y de la necesidad de acercarse a ella para la comprensión del jasidismo.

En el jasidismo la danza está destinada a reproducir el acto creador de Dios que se renueva en el hecho de quienes participan en ella, particularmente sus maestros, los cuales por medio de la danza demuestran y expresan la alegría de vivir, lo cual tenía como base «la idea de que la creación ha sido el resultado de un acto amoroso de Dios hacia los hombres [...] debecut era una expresión de alegría por la presencia de Dios en el mundo» (Laenen, 2006, p. 256). Así, la danza aparece en los relatos como motivo temático en cuanto refleja la vida de los maestros de las comunidades con su «conducta gozosa de los jasidim» (Laenen, 2006, p. 262), en la que se pone de manifiesto la alegría por la plenitud vivida que impregna la cotidianidad.

Estos relatos en los que la danza posee una presencia reiterada, Buber los enmarca en el ámbito de «realidad legendaria» en la cual las personas que allí hablan no hablen de sí, «sino de aquello que las conmovía y, en consecuencia, lo que sabemos a través de ese relato no es solamente un hecho en el sentido psicológico sino también una realidad vital» (Buber, 1993, p. 21). Al aplicar esto a los cuentos donde la danza se hace presente, es posible reconocer que detrás de cada danza hay una pregunta para formular a quien realiza la acción siguiendo esta dinámica señalada por Buber: ¿qué conmueve a quien danza para hacer dicho acto?

\subsection{Los relatos seleccionados y sus elementos de estructura narrativa en relación con la danza}

Los relatos seleccionados con la danza como motivo temático de la trama y de los que se considerarán algunos elementos de la estructura narrativa (extensión, tipo de narrador, destinatario, coordenadas narracionales), son los siguientes: en Los primeros Maestros I (1993) de Israel Ben Eliezer el Baal Shem Tov: «Saúl e Iván» (p. 101), «La danza de los jasidim» (p. 110), «El maestro también danza» (p. 110) y «El sordo» (p. 110). En Los primeros maestros II (1980), de Levi Itzjac de Berditchen: «La danza» (p. 77), 
«Enfermedad y fortaleza» (pp. 141-142). Posteriormente en Los maestros continuadores I (1983), siendo en el que más se encuentran, de Moshe Leib de Sasov: «Un judío vive aquí» (p. 56), «La danza de la curación» (p. 63), «La danza nupcial» (p. 63), «Es el tiempo de danzar» (p. 64); de Menejem Mendel de Rymanov: «La canción de alabanza» (p. 99); de Mordejai de Lejovitz y sus descendientes: «El alma renovada» (p. 119), «En tu Reino» (p. 132). Finalmente, en Los maestros continuadores II (1983b), de Naftalí de Roptchitz: «¡No detenerse!» (p. 41); de Schlomo Leib de Lentshno: «El intrépido» (p. 42); de Simja Bunam de Pzhysha: «En el exilio» (p. 107) y «Actitudes fundamentales» (p. 169).

Entre los elementos de estructura narrativa resalta ante el lector de los Cuentos jasídicos la brevedad de los relatos. Cada uno tiene en promedio ciento cincuenta palabras, siendo pocos los que logran ocupar tan solo una página. En las poéticas del cuento, varios autores, entre ellos Chéjov y Poe, han enunciado esta característica como propia de este tipo de relatos. Edgar Allan Poe (1842) lo afirma desde la que él denominó «unidad de impresión» en la que buscando un «efecto único y singular» (Zavala, 1995, p. 17) el escritor toma uso de la no extensión del relato para no ver impedida la interrupción de la lectura. Así, la brevedad de los relatos permite lograr la impresión buscada por el escritor que desea transmitir la idea que a través de la obra y palabra del tzadik se quiere comunicar ${ }^{4}$.

Esta brevedad está dada tanto desde la extensión como desde la sencillez de la narración, asimilándose al concepto de «concisión» que Antón Chéjov (1895), en una de sus cartas, reclamaba como elemento que da vida a las obras breves, liberándolas de elementos floridos y sobrecargados en los relatos (Zavala, 1995, p. 25). Buber (1993) llamó a esta concisión «narrativa condensada», en la que «la psicología y el ornato deben ser evitados», ya que como señala él mismo, «cuanto más “desnuda” es [la narración], tanto más adecuadamente cumple su función» (1993, p. 21), de ahí que el estilo de los cuentos sea a la vez simple y sin excesos en las descripciones de personajes o lugares.

En esta concisión y condensación, la danza hace su aparición en los relatos sin detenimiento en su descripción por parte del narrador. Se describe el salto inesperado a danzar del tzadik o la realidad de una comunidad en círculo danzando sin profusión de

3. Los Cuentos jasídicos pueden ser comparados en la teoría literaria a los apólogos, narraciones breves cuyo objetivo ético es puesto de relieve al inicio o final de ella.

LINGÜÍSTICA Y LITERATURA

456

ISSN 0120-5587

E-ISSN 2422-3174

N. ${ }^{\circ} 78,2020451-477$ 
detalles, poniendo de relieve que el valor de la danza no está en la forma como se realiza o describa sino en ella misma.

Frente a este elemento de la brevedad, Enrique (2018) en una conferencia de 1982 señala que:

la brevedad del cuento tiene la virtud de ceñirse a los impulsos cortos con que actúa la vida [...] la literatura es siempre expresión de la vida, pero dentro del género narrativo, el cuento es el que más cerca está de la espontaneidad de la vida (Anderson Imbert, 2018, p. 22).

La danza en los cuentos, marcados por la brevedad en su extensión, como es el caso del ejemplo, cumple con la función de transmitir el impulso de la espontaneidad, de lo que abarca al hombre en un instante y sin preconcepción se desborda en la danza.

Respecto al tipo de discurso se reconoce una mezcla de discurso directo e indirecto. Los cuentos son textos donde el discurso directo se usa para resaltar las palabras que el narrador quiere transmitir. Generalmente, se refiere el discurso directo para dar la voz a los personajes en aquello que es determinante en el objetivo de la historia. En la lectura de los relatos, el tipo de discurso permite reconocer la importancia gradual de lo que se enuncia, siendo la mayor la que está unida al discurso directo, comúnmente presente para introducir la frase central de la narración.

A la vez, los cuentos son diálogos en los que se resalta a través del narrador la palabra que quiere darse a conocer para cumplir el fin que se busca al narrar dicha historia. Cada uno de los relatos posee una acción y una palabra con la que se acompaña o explica esa acción del tzadik. En el caso del presente análisis, la danza es la acción que acompañada de una palabra no del narrador, sino del personaje de la trama el cual permite adquirir el sentido. De este modo, la palabra del personaje en cada cuento tiene como objetivo no describir la danza, sino comprender su sentido en el relato particular.

Respecto al narrador, los cuentos presentan un tipo de narrador extradiegético, el cual, como lo describe Imbert (2018), «es capaz de penetrar tan profundamente en la conciencia de los personajes que, en esas profundidades, encuentra aún aquello que los mismos personajes desconocen» (p. 61). En los Cuentos jasídicos, este tipo de narrador si bien no está en la trama del estrato primario, conoce los distintos planos de la narración y a quienes en ellos intervienen. 
De igual modo, en su carácter de extradiegético, el narrador es también heterodiegético, no es sujeto participante en la historia, sino como describe Serrano (1996) a este tipo de narrador, que se muestra como un sujeto poseedor de una competencia cognitiva y semántica, acerca de cuyo origen no puede afirmarse nada textualmente válido. Es él quien decide qué se narra u omite en la brevedad de los cuentos, o como lo afirmó Anderson Imbert, es quien posee la capacidad de seleccionar libremente si ofrecer un vasto cuadro de la vida humana o una escena de concretísimos pormenores (2018, p. 60). En la lectura, el narrador como heterodiegético, asume la voz de la tradición jasídica que ha sido testigo de la vida del tzadik y que selecciona qué narrar eligiendo su importancia para quien se acerca a los cuentos. Sucede con este tipo de narrador, como en el discurso directo, en el que ambos elementos narrativos ponen de manifiesto una selección consciente sobre qué necesita ser narrado y cómo.

Respecto a la danza, el hecho de que el personaje dentro del relato sea quien tome palabra sobre ella, no el extradiegético, transmite la realidad de un acto que sólo es posible vivir al interior de la diégesis y que, en su acción simbólica, propia de todos los actos que realizan los tzadik, llama al lector al ingreso en la trama para su comprensión y participación. Los cuentos que poseen la danza como motivo temático hacen a través del tipo de narrador una llamada al ingreso en el sentido de lo que la acción implica y que transmite el relato.

El destinatario inicial de los cuentos o el «lector modelo» usando la terminología de Umberto Eco (1996, p. 17), es tanto la comunidad jasídica o cada jasid que se interesa por escuchar las historias de sus maestros y por eso conoce el contexto mínimo para comprender la historia: la genealogía del maestro, el calendario religioso judío para enmarcar la temporalidad del relato, así como las características propias de cada lugar en el que se enmarca el relato.

En cuanto a las coordenadas narracionales, la primera de ellas, las temporales, están dadas desde un tiempo crónico limitado al momento breve en que se enuncia el hecho de lo sucedido con el jasid: una noche, el día que se celebra algo específico («El maestro también danza», 1993, p. 110), tras la muerte del hijo mientras avanza el féretro («La danza», p. 1980, p. 77), o en una cena («Un judío vive aquí», 1983, p. 55). 
Desde el punto de vista de su posición temporal con relación a la historia, los cuentos son de tipo narración ulterior, en los que la historia es relatada en pretérito, ella se situa en el pasado con respecto al presente de la narración. Este movimiento temporal en los relatos resalta la importancia del acto de la danza sucedido, el cual no sólo se rescata de la historia, sino que se trae al presente de la narración para significar el porqué de la danza en la comunidad y su acción dotada de sentido que se quiere transmitir.

Un elemento importante a resaltar es que la temporalidad de los cuentos es una temporalidad religiosa propia del calendario litúrgico judío que enmarca la cotidianidad. Los relatos siguen la temporalidad judía de fiestas, celebraciones y las oraciones propias de cada día como ubicación temporal, a los cuales también se unen la historia y su sentido con el tiempo judío que la enmarca, ampliando así su horizonte significativo. Es así como se encuentran las siguientes ubicaciones temporales: En la fiesta de Simjat Torá ${ }^{5}$ («La danza de los jasidim»; 1993, p. 110), en el día del Regocijo en la Ley («¡No detenerse!», 1983b, p. 41), el día de Año Nuevo ${ }^{6}$ («En el exilio», 1983b, p. 107) y el Shabat $^{7}$ («Un judío vive aquí», 1983, p. 56).

En relación con estas coordenadas temporales la danza emerge como un hecho concreto que exige ser narrado. Los cuentos no relacionan danzas que se repetían permanentemente, sino que narran lo excepcional, algo que tuvo lugar en un momento específico, que llama la atención y que se hace necesario trasmitir para no perder.

Asimismo, la danza marcada por la temporalidad religiosa adquiere un doble aspecto: no hace parte del ritual religioso en que se enmarca, es un acto no religioso dentro de lo religioso; pero adquiere su carácter religioso en cuanto brota del tiempo y situación en que la narración la enmarca. Como bien lo afirmó Pieper (2006) en su ensayo Una teoría sobre la fiesta, «hay fiestas mundanas, pero no profanas» (p. 44), es por ello que la danza en los Cuentos jasídicos pone de manifiesto que en la vida jasídica no hay separación entre lo

4. Festividad judía que significa «regocijo en la Ley», como también en otros momentos es llamada. En ella los rollos de la Torá son sacados del arca que los contiene y llevados a través del lugar destinado para la oración en una procesión festiva.

5. Llamado en hebreo Rosh Ha-shaná, el cual se celebra el primer y segundo día de Tishrí, mes de inicio del año en el calendario hebreo.

6. Día séptimo de la semana, declarado sagrado, dedicado a la oración y el compartir en la comunidad tanto del hogar como en el lugar de la reunión religiosa. Comienza en el atardecer del viernes hasta el atardecer del sábado. Su significado deriva del hebreo «descansar». 
sacro y lo profano. En ambas instancias, ella es un acto que manifiesta la religiosidad de lo cotidiano en los pertenecientes al movimiento.

En las coordenadas espaciales, los espacios de desarrollo de los cuentos son: la casa («La danza de los jasidim», 1993, p. 110; «Es el tiempo de danzar», 1983, p. 64; «La danza de la curación», 1983, p. 63; «¡No detenerse!», 1983b, p. 41), la mesa («Saúl e Iván», 1993, p. 101; «En tu Reino», 1983, p. 132), la Casa de Oración («El maestro también danza», 1993, p. 110; «Enfermedad y fortaleza», 1980, 141), la posada («En el exilio», 1983b, p. 107), y la espacio-temporalidad del Shabat («¡Un judío vive aquí!», 1983, p. 55). Todos estos espacios poseen como característica común el ser lugares de encuentro.

La lectura de los relatos con este ambiente de cotidianidad permite captar al que se acerca a los Cuentos jasídicos, que la danza abarca los diversos espacios de la vida humana, tanto los específicamente religiosos como los que no lo son.

Esta no restricción de lugar en los relatos para danzar le concede a la danza un poder de conmoción, como se mencionó anteriormente, que desborda al personaje y le lleva a expresar esta conmoción a través de la danza en cualquier momento o lugar. Precisamente, este carácter de cotidianidad de la danza es lo que permite en la lectura la sorpresa del acto de la danza, ya que al poder darse en cualquier momento suscita la admiración y exige también vincular el acto de la danza a su espacio y tiempo para su interpretación.

Asimismo, en los relatos hay referencias a textos bíblicos y a palabras de las oraciones de la piedad del jasidismo. Los cuentos son palabras que preguntan por palabras, por su sentido y significado, por el cómo sucedieron, es la palabra del cuento que se cuestiona por la palabra de la Escritura, deseando comprenderla en el hoy y mostrar así otra de sus perspectivas.

Buber hace uso de la herramienta de la intertextualidad al tomar palabras de otros textos para poner en los cuentos, poniendo así el texto del cuento en conversación con el de la Biblia para preguntar por él, a la vez, que deja que dicho texto le confronte y explique. Esta intertextualidad es una forma de hacer dialógico el propio cuento, el texto citado bien sea de la Biblia o de la tradición se vuelve un personaje que entra a hacer parte del movimiento de danza. 
Es así como sucede en ¡Un judío vive aquí! donde el anfitrión, Rabí ${ }^{8}$ Elimélej pide a quien le recibe en la mesa recitar un trozo de la Torá, lo cual hace y después continúa explicando las palabras leídas, siendo las palabras de la explicación las que llevan al anfitrión a danzar y exclamar: «¡un judío vive aquí!» (1983, p. 56). En el relato, las palabras citadas y expresadas entran en conversación: La palabra leída en la Escritura, seguida de las palabras que comentan el texto y que suscita en quien ha escuchado un salto a la danza con la palabra, se repiten como hallazgo en la interacción intertextual. Por lo tanto, en Buber hay «danza» de palabras que dialogan al interior del relato.

Como movimiento suscitado por un encuentro del tzadik con una palabra determinada, la danza expresa que la palabra no sólo es herramienta de comprensión del sentido de la acción de danzar, sino que una palabra, en el caso de los cuentos, traída de la vida jasídica, es causa de conmoción de la persona para lanzarla a la danza, la cual es en estos relatos expresión del poder de conmoción de la palabra en los hombres.

\section{3. «Cada uno de sus pasos tenía un significado sagrado...»": El marco y los contextos en los que la danza se desenvuelve en los Cuentos jasídicos}

En este apartado se abordarán cuatro contextos donde la danza aparece como motivo temático en los cuentos seleccionados: lo incomprensible, la identidad, la comunidadamistad y la muerte. Se empezará con el diálogo como marco narrativo de los cuentos jasídicos utilizados en el presente análisis, a fin de encontrar tanto en las situaciones como en el marco otros elementos que permitan profundizar la significación de los pasos de la danza en los relatos.

\subsection{El marco dialógico de los relatos}

7. En los cuentos se encuentran los títulos de «Rav» y de «Rabí». El primero de ellos designa al líder de la comunidad religiosa y que vela por el cumplimiento de la Ley en ella; mientras que el segundo hace referencia al líder del grupo jasídico local, siendo en algunas circunstancias la misma persona para ambos servicios.

8. Del cuento «Es el tiempo de danzar» (1983, p. 64). 
Hay un marco común en los relatos de los cuentos: el diálogo. Los Cuentos jasídicos están mediados por una situación dialógica en la que se da la diégesis propia de cada relato. En el caso de los cuentos seleccionados, la danza se encuentra abarcada por ese dialogo concreto que se realiza entre dos rabinos, o el maestro y la comunidad o algunos personajes que conversan en torno a la vida del tzadik o un elemento del jasidismo.

A partir de los cuentos seleccionados, es posible reconocer los siguientes: Saúl e Iván, quienes en un principio dialogan, llevando luego a este último a danzar por la mutua identidad reconocida (Saúl e Iván, 1993, p. 101), el diálogo entre el Baal Shem y su esposa tras ver bailar a los discípulos en su propia casa (La danza de los jasidim, 1993, p. 110), el maestro en diálogo con la Torá llegado a danzar con ella (El maestro también danza, 1993, p. 110), la imposibilidad del sordo de dialogar con quienes danzan dada su no comprensión de la música (El sordo, 1993, p. 110), los jasidim que manifiestan al rabino su asombro por danzar ante el féretro (La danza, 1983, p. 77), el diálogo del rabí enfermo ante quienes no confían en sus fuerzas (Enfermedad y fortaleza, 1980, p. 142), el encuentro de Moshé Leib en su visita a Rabí Elimélej (Un judío vive aquí, 1983, p. 55), el tzadik que pide no le retengan al bailar y cuenta un relato para justificarse (Es el tiempo de danzar, 1983, p. 64), el rabí de Roptchitz con los jasidim que los anima a no detenerse en su ronda de danza ( $N o$ detenerse!, 1983b, p. 41), el diálogo de quienes preguntan a Rabí Zvi cómo había permanecido fiel a su amigo Rabí Schlomó, siendo éste de otra escuela (El intrépido, 1983b, p. 42).

El diálogo es, pues, el marco de las historias en cuanto cada relato, haga o no explícito el encuentro, menciona en su gran mayoría de veces a alguien, sea el tzadik o un jasid que cuenta a quien pregunta o a la comunidad una historia sobre el maestro o sobre la temática en cuestión. Los Cuentos jasídicos son relatos dialógicos de encuentros entre yo-tú, para afianzar el diálogo o la relación entre quienes se relacionan. El diálogo, en consecuencia, permite delimitar los personajes, pero también hace a otros testigos de lo que allí se narra dentro del mismo relato y por fuera al lector.

Este encuentro entre yo-tú es determinante en el pensamiento de Buber y su presencia en los cuentos establece la relación tanto con su obra filosófica como literaria. En su libro Yo y tú, el filósofo planteó que dichos pronombres son las «palabras primordiales» (1969, 
p. 9), las cuales indican relaciones que se establecen entre los hombres y son las que dan lugar a la existencia auténtica. El hecho que la danza surja de un encuentro yo-tú, pone de manifiesto que ella dentro de los relatos es una acción de relación y su sentido de vida expresa que allí donde aparece en los cuentos es porque ha surgido un auténtico encuentro entre los personajes.

De forma reiterativa la figura del tzadik es la que da la pauta de este marco dialógico al ser él mismo figura de encuentro, ya que «estos personajes son hombres que dialogan y por eso se sienten vivos, porque hay una alteridad que los sitúa en la tierra y frente al cielo, y propicia el encuentro» (Ánjel, 2016, p. 60). La vida que transmiten los cuentos se da por el diálogo que expresa la existencia auténtica, la que los tzadikim viven y en sus encuentros hacen partícipes a los demás.

Los cuentos con la danza como motivo temático buscan a la vez crear y permitir ese diálogo entre el lector y quienes escuchan dentro del relato lo que acontece. El mismo Buber (1969) afirma que «la finalidad de la relación es el ser propio de la relación, es decir, el contacto con el Tú» y que la participación en la relación es «tanto más perfecta cuanto más directo es el contacto con el Tú» (p. 60). La danza es no sólo aproximación corporal sino una verdadera participación del yo en el tú del otro, bien sea en la singularidad o en el de la comunidad, dado que en los Cuentos jasídicos quien danza con otro u otros lo hace no solo desde una cercanía física, sino en cuanto comunión con un tú.

En Buber el concepto de comunidad es comprendido como una unión profunda de unos con otros en viviente reciprocidad y relación mutua de sus miembros con un centro viviente $(1969 \text {, p. 46 })^{10}$. En el caso de los relatos, este «centro viviente» lo es el tzadik en cuanto encarna el espíritu del jasidismo, es por eso que varios de los cuentos con el motivo temático de la danza enfatizan esta realidad de comunidad y unión al mostrar la comunidad danzando, como sucede en «La danza de los jasidim» con el círculo de anillo de fuego azul que contempla la mujer del Baal Shem al entrar en la sala donde danzan los discípulos de su esposo (1993, p. 110), en «La danza nupcial» a través del círculo formado por los invitados en cuyo centro termina danzando el tzadik (1983, p. 63) y en «¡No detenerse!»

9. Para Buber la diferencia entre colectividad y comunidad radica en que esta última se distingue porque en ella no se está el uno junto otro, sino que se está uno con otro en pluralidad de personas (2006, p. $160)$.

LINGÜÍSTICA Y LITERATURA 
donde la gran ronda en el patio del tzadik no se suspende tras la noticia de la muerte (1983b, p. 41). La danza realizada por distintos sujetos en los relatos resalta el elemento comunitario del encuentro puesto de manifiesto en la danza formada por varios en círculo.

\subsection{Los contextos en los que se danza en los cuentos}

En medio de este marco dialógico hay cuatro contextos que son posibles de reconocer como recurrentes de la danza en la lectura de los Cuentos jasídicos y que permiten comprender la presencia reiterada de ella en los relatos.

El primer contexto, lo incomprensible, está dado por las imágenes de la contradicción con que se describe y acompaña la realidad de la danza: una «canción jasídica sin palabras que llegó en línea directa a los pies de los aldeanos» (Saúl e Iván, 1993, p. 101); el hombre sordo que al pasar por allí «le pareció que todos actuaban como locos, desprovistos de gracia y de sentido», pero no aludiendo a su discapacidad auditiva sino a «que nada sabía de música» (El sordo, 1993, p. 110); o a que una de las características de un verdadero judío sea «danzar sin movimiento» (Actitudes fundamentales, 1983b, p. 169).

A través de estas imágenes de contradicción se expresa la danza como una realidad que trasciende el acto de bailar para mostrarse como un elemento inherente al jasidismo y que exige una comprensión de nivel superior para poder captar la totalidad de su sentido. Lo incomprensible lanza a la búsqueda permanente para obtener una respuesta frente al sentido de la acción del tzadik.

De igual modo, las danzas en los relatos poseen el carácter de lo inquietante: se pregunta el por qué se danza ante el féretro (La danza, 1980, p. 77); cómo es posible una danza sin movimientos, gritar en silencio (Actitudes fundamentales, 1983b, p. 169) o ser sordo y poseer sentido de la música (El sordo, 1993, p. 110); sorprende encontrar un hombre en situación de destierro y desgracia bailando (1983b, p. 107); cómo el rabino baila con la Torá y luego la suelta y sigue bailando (En el exilio, 1993, p. 110). En cuanto realidad humana, la danza es inexplicable totalmente en los relatos dado que es reflejo de lo inabarcable del hombre: el dolor, la muerte, la alegría. Cada uno de los pasos de la danza, 
como los de Rabí Moshé, son «un misterio poderoso» (La danza de la curación, 1983, p. 63).

El segundo contexto en los relatos con referencia a la danza es la identidad, expresada particularmente en tres de los cuentos. En Saúl e Iván en el encuentro del muchacho y el campesino que al ritmo de la melodía lleva a Iván tras haberle preguntado al primero su nombre a repetir de forma eufórica: «TTú Saúl y yo Iván, tú Saúl y yo Iván!» (1993, p. 101). Ante el joven que danza, el campesino expresa la identidad de ambos que en el júbilo de la danza manifiesta el mutuo reconocimiento que en ella se da.

En Un judío vive aquí, la relectura del relato del éxodo israelita de Egipto lleva a Rabí Elimélej, quien ha escuchado la narración de Moshé Leib, a identificarse con la casa de un judío auténtico de aquella historia, que lo lleva a bailar y a cantar la misma expresión con la que se siente retratado: «iun judío vive aquí!» (1983, p. 53).

Por otra parte, la danza como vehículo de la expresión y descubrimiento de la identidad, a la vez que expresión de la libertad, es trabajado en el relato El intrépido, en el que Rabi Shlomó ante el miedo por su maestro Rabí Zvi Elimélej de Dynov, cuando los demás no osaban levantar los párpados para mirarlo, «se quitó los zapatos y danzó sobre la mesa exactamente delante del rabí, y éste permaneció sentado, observando, y no pronunció una palabra» (1983b, p. 42). La danza es, pues, la libertad de la identidad que permite al rabino rebelarse ante el miedo.

En estos relatos hay una situación común de sorpresa ante lo que se halla en sí mismo y que confluye en la danza. En Saúl e Iván, la identidad unida a la reciprocidad; en ;Un judío vive aquí!, la corroboración de la propia fidelidad al jasidismo de rabí Moshé; y en El intrépido, la libertad que en su interior descubre el alumno ante su maestro. El instante del descubrimiento de lo propio como humanos lanza a la danza.

El tercer contexto, en cuanto vinculación relacional, está dado desde el ámbito de la comunidad y de la amistad. Respecto al primero, puede resaltarse el relato La danza de los jasidim en el que la mujer del Baal Shem, al entrar al salón, contempla a los discípulos de su esposo «danzando en círculo y en torno de la rueda ardía un anillo azul» (1993, p. 110), exponiendo en esta imagen la unidad de aquellos que bajo un mismo maestro y melodía permanecen con el lazo de la vida de condiscípulos. En otro cuento, La danza nupcial, se 
da en el ámbito de la boda del nieto de Rabí Moshé Leib, en la que el mismo rabí, sin ser reconocido, baila solo en el medio del círculo formado en la danza (1983, p. 63).

La danza, realizada por un conjunto de personas —en el caso del jasidismo, sólo hombres - pone de relieve la cohesión de la comunidad que se une para compartir un sentimiento y celebrar algo determinado, tanto religioso como propio de la cotidianidad. La imagen del «anillo azul» en torno a la rueda formada por los danzantes expresa en términos de alianza la unidad de la comunidad en danza.

Frente a la amistad, destaca el relato La danza de la curación, en el que ante la noticia dada a Rabí Moshé de la enfermedad de su amigo el rabí de Berditchev en el Shabat, el primero repite el nombre del enfermo varias veces, tras lo que «se puso sus zapatos nuevos de cuero marroquí, se los anudó ajustadamente y bailó», a lo que uno de los allí presentes afirmó: «una fuerza fluía de su baile. Cada uno de sus pasos era un misterio poderoso» (1983, p. 63).

En este relato, un elemento que se vincula a la amistad es el repetir el nombre del enfermo por parte de Rabí Moshé y el danzar en el día del Shabat como plegaria por su amigo enfermo. La noticia del amigo desata el repetir su nombre como vinculación a la persona, así como en Saúl e Iván, pero también la celebración por la vida de la persona. Precisamente, en su ensayo Distancia originaria y relación, Buber afirmó que el llamar al otro y hacerlo por su nombre es propio del ser humano, así como el dirigirle la palabra al otro es ya un reconocimiento de su alteridad y de la relación que con él se entabla (2006, p. 182). La unión en el relato del acto de repetir el nombre y el baile que sucede tanto en $L a$ danza de la curación y en Saúl e Iván lleva a la posibilidad de la relación en el descubrimiento del otro cuyo nombre se menciona y con el que se establece y expresa el lazo creado en la danza.

Por último, respecto a la muerte, dos relatos explicitan esta relación con la danza. El primero es La danza, en el que se narra cómo tras la muerte de su hijo, Rabí Leví Itzjac sigue el féretro danzando (1980, p. 77) causando la conmoción de sus jasidim. El segundo es ¡No detenerse!, cuyo contexto es la muerte inminente del rabí de Ulanov, amigo del rabí de Roptchitz. Los jasidim de esta última localidad estaban ya danzando en ronda en el patio de la casa del tzadik mientras él los miraba sonriendo. Tras la mano levantada, la pausa de 
la danza y una nueva seña por parte del rabí, éste les dice: «Cuando uno de los generales cae en la batalla, ¿deben sus soldados dispersarse y huir? ¡La lucha continúa! ¡Alegraos y bailad!»(1983b, p. 41). El narrador agrega que luego se supo que en aquella misma hora había muerto el rabí de Ulanov.

Sobresale de este relato la imagen de la danza como lucha que continúa mientras se baila al ritmo de la melodía. La danza adquiere el carácter de resistencia ante el dolor e infortunio, pero de resistencia en conjunto, como lo expresa la no dispersión de los «bailadores-soldados». Incluso, si los que danzan son los jasidim tras la muerte del rabí, su danza es un signo de la continuación en ellos de la vida del maestro, así como de la permanencia de la enseñanza recibida, de su conducta gozosa.

En el caso del cuento Es el tiempo de danzar, lo hace desde quien se acerca a la muerte. De este tzadik innominado se afirma que estando «al borde de la muerte se levantó y bailó». Y cuando los que lo rodeaban trataron de detenerlo, les dijo: «Este es el tiempo de bailar» (1983, p. 64). En esta historia se inserta otra, en la que se cuenta que el Rabí Uri de Strelisk, al pedirle dinero al rabí de Sasov para obras de caridad, éste le contestó: «No tengo dinero, pero bailaré un poco para ti», para decir hacia final de la historia, estando ya al borde de la muerte: «Por eso digo que cuando lleguen a ti con un requerimiento, es el tiempo de bailar». Por lo tanto, al que está por pedírsele la vida, descubre que es el tiempo de bailar.

En concreto, la danza, que es la propia vida de quien la realiza, es la paga para el otro, desde la historia del Rabí Uri y del tzadik al borde la muerte quien la narra. Detrás de este relato está la función del cuento jasídico: ser no solo un ars vivendi, sino también un ars moriendi. La alegría del jasidismo abarca la muerte en una danza.

\section{4. «AAlegraos y bailad!» ${ }^{11}$ El diálogo celebrativo y su «esfera» de movimiento}

La danza como diálogo celebrativo es la propuesta de lectura y análisis de los cuentos seleccionados, estableciendo la relación con el pensamiento dialógico de Martin Buber como puente entre sus textos literarios y filosóficos.

10. Del cuento ;No detenerse! (1983b, p. 41). 


\subsection{La danza como «esfera del entre» en los Cuentos jasídicos}

La danza, como lo reflejan los Cuentos jasídicos, es una acción que se deriva del diálogo. En ella, el efecto del encuentro se manifiesta no como algo controlado, sino en condición de desborde, de ahí lo sorpresivo de la danza en el contexto de los relatos: en un funeral (La danza, 1983, p. 77), en la enfermedad (;No detenerse!, 1983b, p. 41), en la sala de una casa (La danza de los jasidim, 1993, p. 110) o una posada en un contexto inesperado (En el exilio, 1983b, p. 107). La danza es la manifestación de lo inabarcable que se da en el ser humano a partir de una experiencia de encuentro entre yo-tú, bien sea con otro personaje dentro del relato o una palabra con la que se entra en diálogo.

En ese sentido, resulta interesante que la forma del desborde de lo sucedido sea la danza, porque ella abarca la totalidad del ser humano desde su corporeidad en la fusión de la música con el latir del corazón hasta su espíritu que se ve elevado, por lo cual le lanza a celebrar. La danza refleja el toque profundo y global que en el hombre suscita el diálogo, indica que este no es algo sucedáneo o teórico, sino existencial, corporal y de conmoción, como lo afirma el mismo Buber de este tipo de relatos (1993, p. 20).

La danza es, además, un acto que conmueve por el diálogo sucedido en la persona. La relación entre la danza y el diálogo, como propia de los cuentos, es atestiguada por la acción de danzar en los Cuentos jasídicos, donde ella se desarrolla durante el relato como elemento del cuento que hace quiebre en la trama: lleva a Iván a repetir su nombre mientras danza junto con el de Saúl (Saúl e Iván, 1993, p. 101) sorprendiendo a quienes contemplan la escena; inquieta a quienes ven su maestro bailando solo (El maestro también danza, 1993, p. 110) o a quienes incluso llegan a cuestionar al Rabí Leví porque danza ante su hijo muerto (La danza, 1980, p. 141); ante el suspenso de noticias de muerte o enfermedad, se pasa a la alegría tras iniciar el tzadik a bailar (La danza nupcial, 1983, p. 63; Es el tiempo de danzar, 1983, p. 64; ;No detenerse!, 1983b, p. 41). La danza, entonces, indica el cambio de la situación donde se hace presente.

En su texto Yo y tú, Buber sostuvo que «toda vida verdadera es encuentro» (1969, p. 16), si la danza es expresión de lo sucedido en el encuentro, es a la vez acción simbólica de la autenticidad del encuentro vivido en los relatos, es celebración de la existencia auténtica 
que únicamente es posible vivir en dicho encuentro. La danza en los Cuentos jasídicos es diálogo celebrativo del encuentro entre yo-tú, el cual adquiere en ella el carácter de fiesta del encuentro vivido, y lo celebra dejando que el diálogo exprese sin contenerse los efectos de lo acontecido en el interior.

En relación con lo anterior, el concepto del encuentro entre yo-tú en el pensamiento de Buber está dado por una categoría específica que él denominó la «esfera del entre» (en alemán, Zwischen). Esta es la esfera en la cual, según Buber, se da el encuentro y el diálogo, pues este no se realiza en el yo ni en el tú, ni en un terreno aparte de ellos, sino «entre» el yo y el tú, en una esfera a la que sólo ellos tienen acceso y a la que ellos únicamente conforman. Como diría el mismo Martin Buber en uno de sus libros principales ¿Qué es el hombre?, al hablar de la «esfera del entre»: «Más allá de lo subjetivo, más acá de lo objetivo, en el "filo agudo" en el que el "yo" y el "tú" se encuentran se halla el ámbito del "entre"» (1982, p. 149). En consecuencia, la «esfera del entre» de cada encuentro es única, dado que es en ella donde se genera la relación del yo y el tú, por lo que ninguno de las dos la posee, pues únicamente se da en el encuentro.

En sentido amplio, cada persona en diálogo con otro entra en una «esfera del entre» distinta, nunca repetida, y por ello ninguna forma de la danza es igual a otra. Si bien se poseen elementos comunes, cada danza es única en sus características y contexto, por lo que representa un cuento propio con personajes y características singulares.

En este punto, se puede proponer que en los Cuentos jasídicos la danza posee el carácter de «esfera del Zwischen» pues en ella se da el «filo agudo» del encuentro que no depende de una persona, sino de quienes entran en relación en el círculo de dicha danza, bien sea entre la comunidad de los jasidim, entre quienes se encuentran en lo individual o incluso en quien danza con la Torá.

Como «esfera del entre» la danza en los relatos permite también la participación en el diálogo del lector, quien entra en dicha esfera y participa en el silencio, como lo hacen los diversos testigos en cada cuento de la danza. Es importante señalar que si bien en varios de los relatos seleccionados la danza la realiza sólo una persona: el rabino ante el cuerpo yaciente de su hijo (La danza, 1980, p. 77), el rabino enfermo (Enfermedad y fortaleza, 1980, p. 141-142), el rabino que bailando canta: «un judío vive aquí» (Un judío vive aquí, 
1983, p. 55), el emisario que enferma y luego danza alrededor de la mesa (En tu reino, 1983, p. 132), el alumno valeroso que danza ante el maestro (El intrépido, 1983b, p. 42); la danza no es un acto individual sino comunitario, porque abarca a todos los que hacen parte de la escena-relato.

Asimismo, la danza como «esfera del Zwischen» es el espacio de la realidad, en cuanto «construcción a partir del encuentro y la transformación de las partes que intervienen en la experiencia» (Ánjel, 2017, p. 21). En la danza, el diálogo se manifiesta en cuanto tejido de preguntas y respuestas, como sucede en Saúl e Iván: «¿Cómo te llamas? "Saúl” fue la respuesta» (1993, p. 101), llevando a quienes danzan a tocar la vida auténtica que allí se genera. En la danza no se huye, se toca y acepta la realidad a la que se ha accedido en el encuentro entre yo-tú, la realidad del otro y la propia de quien baila en el relato, la única realidad existente en Buber.

En los cuentos danzan hombres a los que se les pregunta por el sentido de la muerte, la identidad del otro, la enfermedad, la vivencia auténtica del judaísmo, el miedo. Si el Zwischen «es el campo que recorremos para propiciar la respuesta, que es el encuentro con el Tú» (Ánjel, 2017, p. 31), la danza en cuanto «esfera del entre» es movimiento de preguntas y respuestas que parte de un encuentro y conduce nuevamente a él. Por ello, así como la danza transforma la trama haciendo cambios en ella y sorprendiendo a quienes la contemplan, dando saltos de la enfermedad a la salud, la tristeza a la alegría, la ignorancia al conocimiento, así también ella es esfera de transformación. Quien danza en los relatos es quien se ha dejado transformar en el encuentro. Sus movimientos externos son expresión del movimiento interno ejercido en el diálogo entre yo-tú.

En cuanto «esfera del entre», la danza es según la expresión de Buber, un «filo agudo» de conmoción, unicidad y exclusividad de cada encuentro, transformación, existencia auténtica, percepción de la realidad propia y del otro a través del movimiento de preguntas y respuestas, y vivencia comunitaria. Cada danza en el relato es una «esfera del entre» abierta, que abarca tanto al personaje central, como a la comunidad, los testigos y a los lectore en un único movimiento.

\subsection{La danza como diálogo celebrativo}

LINGÜISTICA Y LITERATURA 
Así como en el segundo segmento, en el que a partir de cuatro contextos se analizó la danza como motivo temático de algunos relatos, desde ellos se pretenderá acercarse al diálogo como celebración, en cuanto lo permite la relación establecida entre los Cuentos jasídicos y el pensamiento filosófico de Martin Buber.

Desde el aspecto de lo incomprensible, la danza celebra lo que es inexpresable en palabras, es decir, el efecto de plenitud que el diálogo genera en cada persona. La función de la danza es la exteriorización de lo que en el interior acontece y se opera en quien vive el encuentro entre yo-tú. Las imágenes de la contradicción usadas por Buber se refieren a lo cierto, pero indescriptible a la vez de la danza. Precisamente, en su texto Diálogo en un apartado llamado «El silencio comunicativo» Buber sostuvo que «el lenguaje puede renunciar a toda manifestación sensible y seguir siendo lenguaje» (2006, p. 125), y por lo tanto, la danza es en su contradicción en los relatos la comunicación silenciosa de lo que late en ellos.

En ese sentido, la danza es el lenguaje en los relatos jasídicos, ya que el acto de danzar comunica en expresividad intensa lo que vive quien danza y lo que experimentan quienes están en torno y contemplan, entre esos el lector. La danza como lenguaje comunicativo expresa «palabras» ante situaciones en las que la fuerza del acontecimiento silencia, pero exige la expresión de quien los encarna: ella «habla» en los relatos en la enfermedad y agonía (La danza de la curación, 1983, p. 63), en la fuerza de descubrir un tú con quien vivir el encuentro (Saúl e Iván, 1993, p. 101) o ante el miedo que aísla (El intrépido, p. 42). La danza es palabra y grito, así como un silencio que comunica con el cuerpo ${ }^{12}$.

A la vez, en los contextos donde se hace presente la danza, ella es también el lenguaje con el que quienes la contemplan sienten que están hablando sobre su alegría (La danza de los jasidim, 1993, p. 110) o sobre la necesidad de continuar ante la adversidad (¡No detenerse!, p. 1983b, p. 41). Dado que la danza se da en la «esfera del entre», al pertenecer al yo y al tú, usando los términos buberianos, ella es lenguaje y celebración de quienes danzan y quienes la contemplan.

11. A diferencia de la tradición griega, en el jasidismo el cuerpo no es comprendido como antagónico al alma, sino como identidad propia del hombre. La idea del hombre está vinculada a la existencia de un cuerpo, de ahí que el cuerpo danzando es en sí la totalidad del hombre puesta en movimiento. 
La danza en los cuentos también expresa lo incomprensible que vive el ser humano, así como la polaridad de la existencia en sus extremos de vida y muerte, tanto para quien experimenta los azares de la vida como para quien se une a la danza o la contempla.

El segundo momento lo brinda el hecho de que la danza permite celebrar el diálogo que lleva al reconocimiento de la identidad propia y del otro. Buber (1982) afirmó como síntesis de su antropología: «Podremos aproximarnos a la respuesta de la pregunta "¿qué es el hombre?" si acertamos a comprenderlo como el ser en cuya dialógica, en cuyo "estardos-en-recíproca-presencia" se realiza y se reconoce cada vez el encuentro del "uno" con el “otro"» (p. 51). Cada uno de los cuentos está construido con base en un encuentro, así que si la danza genera identidad es debido al encuentro que se ha generado entre los hombres, este es el que, en definitiva, permite el reconocerse y celebrarlo luego en la danza.

Sólo en el encuentro ante la presencia del otro es posible entonces la vida real y verdadera, como en el cuento Saúl e Iván (1993, p. 101), cuando lo descubren ambos personajes mientras celebran la identidad propia que con el otro han encontrado y que celebran en la danza. La danza celebra un encuentro de identidades: la propia y la del otro, sea este otro una singularidad o, como ya se ha señalado, una comunidad. Por ejemplo, en ¡Un judío vive aquí! (1983, p. 56), la identidad celebrada es la de pertenecer a un grupo concreto en la que el rabino se halla a sí mismo. La danza es, pues, celebración de una identidad lograda en reciprocidad.

En Yo y Tú Buber (1969) afirmó: «el hombre se torna un Yo a través del Tú» (p. 30). En los Cuentos jasídicos, la danza es expresión de ese movimiento del crecer en la propia identidad no desde el solipsismo, sino desde la relación, como lo hace Iván «en medio de sus salvajes saltos y brincos al repetir más y más alto» su identidad y la de Saúl en el encuentro (Saúl e Iván, 1993, p. 30). En cuanto este movimiento del crecimiento en la propia identidad es permanente, ya que la danza significa también en los relatos la celebración de la posibilidad ininterrumpida de volver a danzar con el otro, tornándose a sí mismo.

Tercero, la danza como diálogo celebrativo que expresa la comunidad y la amistad celebra el diálogo que congrega y forma comunidad. La descripción de la danza circular explícita en algunos relatos (La danza de los jasidim, 1993, p. 110; La danza nupcial, p. 
1983, p. 63) manifiesta la acción de la danza que forja y conserva un grupo en torno a un principio de identidad que es atribuido al tzadik y que en los momentos en que la danza está permeada por la relacionalidad bajo el carácter de la amistad se manifiesta la vida del amigo como digna de ser danzada.

Los relatos aúnan la identidad propia como la pertenencia a la comunidad también a través de la danza. La que se ha denominado como la existencia dialógica que presenta Buber se abre al constructo humano, al ser presentada cada realidad humana como sujeto de diálogo. En su ensayo Elementos de lo interhumano, él afirmó: «Los seres humanos no existen antropológicamente en el aislamiento, sino en la totalidad de la relación entre unos y otros: sólo la acción recíproca hace posible comprender adecuadamente la humanidad» (2006, p. 202). De este modo, la danza como acción recíproca es un movimiento en el que se acoge y comprende la humanidad en el otro.

Por otra parte, la danza en los cuentos, como lo resalta el relato La danza de los jasidim (1993, p. 110) se da no sólo en comunidad, sino que celebra la comunidad en torno a la cual el maestro celebra su unión. Aunque la comunidad se reúne para el estudio, la oración y la escucha, también expresa en la danza tanto lo que viven como el efecto que las palabras escuchadas producen en ellos.

Por eso, la danza celebra en los relatos la posibilidad de reconocerse humano en la construcción de un grupo en el cual cada cual quien no con otro, sino hacia el otro (Buber, 2006, p. 180), celebra la reciprocidad humana, el valor del amigo, el sentirse en contacto en el encuentro entre yo-tú con la humanidad, con lo interhumano.

Por último, se celebra el diálogo que no es interrumpido por la muerte. En ¿Qué es el hombre? (1982), Buber planteó la realidad de la muerte como propia del ser humano. Allí expresó que el hombre:

Cualquiera sea el pueblo, el tipo o la edad a que pertenezca, sabe lo que fuera de él, nadie más en la tierra sabe: que transita por el estrecho sendero que lleva del nacimiento a la muerte; prueba lo que nadie que no sea él puede probar: la lucha con el destino, la rebelión y la reconciliación y, en ocasiones, cuando se junta por elección con otro ser humano, llega hasta experimentar en su propia sangre lo que pasa por los adentros del otro (p. 19).

Este texto de su pensamiento encuentra en los cuentos su respaldo literario. En iNo detenerse! (1983b, p. 41) y en La danza de la curación (1983, p. 63) están representados 
tanto el afrontar el destino de la enfermedad y la muerte como la vinculación profunda que se establece entre la comunidad y el rabino que está en peligro, o cuando a un rabino amigo se le habla del otro que está enfermo y a través de sus actos, entre esos destacándose el danzar, reflejando así la unión profunda con él.

La muerte toca también en los cuentos la finitud humana, la importancia de cada ser humano como un mundo que se acoge. Para Buber (2006): «El diálogo es algo propio de la creación, de la criatura, y eso es el ser humano del que hablo, del que hablamos: una criatura, trivial, pero insustituible» (pp. 163-164). La danza, en cuanto diálogo celebrativo, acoge lo trivial pero insustituible que es el hombre, ante el que incluso en su muerte es posible danzar.

En línea con lo anterior, para el filósofo judío, «solo quien considera al otro ser humano mismo y se abre a él recibe en él al mundo» (Buber, 2006, p. 158). El mundo para Buber como lo pone de manifiesto en sus Cuentos jasídicos, es la realidad tejida en los encuentros humanos, fruto de la apertura recíproca que se da entre los hombres. La danza en sus cuentos es dialógica, abre el mundo de quien danza al mundo de quienes junto con él forman la danza circular, creando así un nuevo mundo, una «esfera del entre», en la que se abre y recibe el universo de los demás. La danza celebra el mundo único que es el otro, ante ese mundo único e insustituible es ante el que se da el movimiento celebrativo.

Al igual, así como en los antiguos la danza tenía como objetivo imitar el universo (Eliade, 1983, p. 157), en los relatos de Buber la danza se da en torno al universo que es el otro, con el que se entabla una relación dialógica de yo-tú que es necesario celebrar y cuya celebración no detiene la muerte, pues el encuentro construido, o la «esfera del entre», no se ve destruida. Esta no destrucción de la relación, del mundo único del otro, es lo que en la muerte celebra la danza.

Finalmente, este diálogo celebrativo se da no en un espacio o tiempo especial, sino en la coordenada de la cotidianidad, como lo señala Scholem (1996, p. 375), y que en los Cuentos jasídicos se vive desde la mesa de la casa hasta en el lugar de la oración. Esta cotidianidad del diálogo es posible en cuanto que donde el ser humano esté presente allí puede vivirlo. Su presencia transforma todo lugar en un espacio dialógico. La danza es entonces la irrupción de lo trascendente en lo cotidiano, ante una realidad común a la 
expresión de la danza que hace ruptura en lo común, manifestando lo extraordinario en lo ordinario, el diálogo que en todo momento es posible establecer y celebrar.

\section{Conclusión: Danzar sin movimiento}

Preguntaron a Rabí Menájem Méndel de Vorki qué es lo que distingue a un verdadero judío. «Tres cosas son propias de nosotros: ponerse de hinojos permaneciendo erguido, gritar en silencio y danzar sin movimiento» (Actitudes fundamentales, 1983b, p. 169).

El acercamiento a la realidad de la danza en los Cuentos jasídicos de Buber y su relación con su pensamiento ha llevado a definir una de las características que menciona el rabí en la historia: danzar sin movimiento. La lectura, pasada por la hermenéutica de la reflexividad (Ricoeur, 2006, p. 20) en cuanto posibilidad de comprensión de sí mismo del lector ante el texto, hace en los lectores la experiencia del despliegue de la celebración del diálogo, que ante cada relato de los maestros jasídicos se puede tener. Cada uno es quien es en la lectura interlocutor del rabino, pero también parte de la danza circular en la que el nuevo mundo y el propio se abren. Por lo tanto, todos forma parte de la "«esfera del Zwischen» que cada círculo de danza abre para todos.

Tras recorrer los segmentos del presente artículo, puede concluirse que:

- Los Cuentos jasídicos de Buber transmiten la vida de los tzadikim a través de palabras y acciones simbólicas, en los que se representa lo esencial del jasidismo y en los que la acción de danzar se hace presente en algunos relatos, manifestando la importancia de la danza en dicho movimiento y el carácter gozoso y festivo que caracteriza la opción jasídica.

—El diálogo es el marco narrativo de los Cuentos jasídicos, en los que el encuentro de un rabí con otro personaje o la comunidad mueve la trama de los relatos. De igual manera, los cuentos en los que la danza es motivo temático tienen como contextos recurrentes lo incomprensible, la identidad, la comunidad-amistad, y la muerte, manifestando el carácter relacional de la danza y su condición de acción simbólica que transmite un sentido de vida.

- La danza es, pues, en los Cuentos jasídicos, lo que en su obra filosófica Buber llamó la «esfera del entre», en la cual se da el auténtico encuentro entre yo-tú, y es a la vez la 
celebración del diálogo realizado que mueve a quien lo ha vivido a esta expresión inesperada y festiva en los relatos.

En definitiva, se considera la presente reflexión como una invitación a «danzar», es decir, a una vida en la plenitud del diálogo que lleva a los hombres a manifestar en lo externo la celebración interna del encuentro yo-tú, el cual permea la existencia de la conducta gozosa de aquellos de quienes los Cuentos jasídicos relatan sus acciones y palabras, poniendo a todos a «danzar sin movimiento».

\section{Referencias bibliográficas}

1. Anderson Imbert, E. (2018). Teoría y técnica del cuento. Barcelona: Ariel.

2. Ánjel, M. (2016). La significación de lo insignificante: (una provocación de lo que nos rodea y nos hace humanos en la teoría de Martín Buber). Medellín: UPB.

3. Buber, M. (1969). Yo y tú. Buenos Aires: Nueva Visión.

4. Buber, M. (1980). Cuentos Jasídicos: Los primeros maestros II. México: Paidós.

5. Buber, M. (1982). ¿Qué es el hombre? México: Fondo de Cultura Económica.

6. Buber, M. (1983). Cuentos Jasídicos: Los maestros continuadores I. Barcelona: Paidós.

7. Buber, M. (1983). Cuentos Jasídicos: Los maestros continuadores II. Barcelona: Paidós.

8. Buber, M. (1993). Cuentos Jasídicos: Los primeros maestros I. Barcelona: Paidós.

9. Buber, M. (2006). Yo y tú y otros ensayos. Buenos Aires: Lilmod.

10. Buber, M. (2014). Die Erzählungen der Chassidim. Zürich: Manesse.

11. Eco, U. (1996). Seis paseos por los bosques narrativos. Barcelona: Lumen.

12. Eliade, M. (1978). Historia de las creencias y de las ideas religiosas: De la prehistoria a los comienzos de Eleusis, Vol. I. Madrid: Cristiandad.

13. Eliade, M. (1983). Historia de las creencias y de las ideas religiosas: De Mahoma al comienzo de la modernidad, Vol. II. Madrid: Cristiandad.

14. Eliade, M. (1996). Historia de las creencias y de las ideas religiosas: Desde la época de los descubrimientos hasta nuestros días, Vol. III. Barcelona: Herder.

15. Friedman, M. (1993). Encuentro en el desfiladero. La vida de Martin Buber. Buenos Aires: Planeta. 
16. Laenen, J. (2006). La mística judía: una introducción. Madrid: Trotta.

17. Pieper, J. (2006). Una teoría de la fiesta. Madrid: Rialp.

18. Ricoeur, P. (2006). La vida un relato en busca de un narrador. Ágora, 25(2), 9-22.

19. Scholem, G. (1996). Las grandes tendencias de la mística judía. Madrid: Siruela.

20. Serrano Orejuela, E. (1996). La narración literaria: teoría y análisis. Cali: Colección de Autores Vallecaucanos.

21. Wittmayer Baron, S. (1968). Historia social y religiosa del pueblo judio: El idioma y la literatura hebreas, Vol. VII. Buenos Aires: Paidós.

22. Zavala, L. (1995). Teorías del cuento I: Teorías de los cuentistas. México: UNAM. 